\title{
СТРАТЕГІЯ ВДОСКОНАЛЕННЯ МЕДИЧНОГО СТРАХУВАННЯ НА ОСНОВІ ПОКАЗНИКІВ ЯКОСТІ НАДАННЯ МЕДИЧНОЇ ДОПОМОГИ
}

\author{
С. О. Джундубаєва \\ Страхова медична компанія АT КК ЗіМС "Інтертіч", Казахстан
}

\begin{abstract}
Розглянуто питання вдосконалення медичної страхової діяльності шляхом створення системи перевірки якості надання медичноїдопомоги. Особлива увага звертається на виявлення лікарських помилок. Незважаючи на складнощі об'єктивізації цього процесу, аналізуються можливі шляхи вирішення проблеми та ризики страхової діяльності.
\end{abstract}

Ключові слова: медичне страхування, якість надання медичної допомоги, ризики страхової діяльності, лікарські помилки, виявлення основної причини.

\section{СТРАТЕГИЯ СОВЕРШЕНСТВОВАНИЯ МЕДИЦИНСКОГО СТРАХОВАНИЯ НА ОСНОВЕ ПОКАЗАТЕЛЕЙ КАЧЕСТВА ОКАЗАНИЯ МЕДИЦИНСКОЙ ПОМОЩИ}

\author{
С. О. Джундубаева \\ Страховая медицинская компания АO КК ЗиМС "Интертич", Казахстан
}

\begin{abstract}
Рассмотрены вопросы совершенствования медицинской страховой деятельности путем создания системы проверки качества оказания медицинской помощи. Особое внимание уделено выявлению врачебных ошибок, что и стало целью данной работы. Несмотря на сложности объективизации этого процесса, анализируются возможные пути решения данной проблемы, а также влияние на риски страховой деятельности. Проанализированы перспективы нормативно-правовой и информационно-математической стратегии выявления врачебных ошибок. В частности, рассмотрены вопросы страхования профессиональной ответственности, позволяющей цивилизованно разрешить конфликты между врачами и пациентами. В то же время прямое использование подобного подхода наталкивается на непонимание медицинскими работниками ряда положений, например, предмета страхования, распределения ответственности между исполнителями врачебных назначений, а также механизмов влияния закона на!снижение количества врачебных ошибок.

Сегодня представляется более практичным использование информационных подходов для выявления врачебных ошибок. При этом подчеркивается, что отправной точкой работы по улучшению качества медицинской помощи являются технологии определения и устранения ее основной причины. Рассмотрены некоторые формализованные алгоритмы: «колесо Деминга», принцип организации выборки, метод опроса, метод проверочного листка, метод гистограмм, диаграмма Парето и другие.

Заметим, что технологические сложности подхода отрицательно влияют на его эффективность. Поэтому наиболее перспективным следует признать использование онтологических представлений о динамике патологического процесса и его стандартизации.
\end{abstract}

Ключєвьіє слова: медицинское страхование, качество оказания медицинской помощи, риски страховой деятельности, врачебные ошибки, выявление основной причины.

\section{STRATEGY TO IMPROVE HEALTH INSURANCE BASED ON THE QUALITY OF MEDICAL CARE}

\section{Insurance medical company "Interteach", Kazakhstan}

Issues of improving the health insurance through the creation of quality systems of care are discussed. Particular attention is paid to the identification of medical errors, and that was the aim of this work. Despite the complexity of the process of objectification, examines possible solutions to this problem, and the impact on the risk of the insurance business are analyzed. The prospects of normative- legal and information- mathematical strategies to identify medical errors are considered. In particular, issues of professional liability insurance, which allows a civilized manner to resolve conflicts between doctors and patients, are examined. At the same time, the direct use of this approach meets with incomprehension medical staff a 
number of provisions, such as the subject of insurance, the allocation of responsibility between the performers of medical appointments, as well as mechanisms of the effect of the law on the reduction of medical errors.

Today, it seems more practical use of information- based approaches for identifying medical errors. It is emphasized that the starting point of the work to improve the quality of care are the technologies of identifying and addressing its root causes. We consider some formal algorithms, "Deming wheel," the organizing principle of the sample survey method, the method of screening sheet, the method of histograms, Pareto charts and others. Note that the process of approach adversely affects its efficiency. Therefore, the most promising should recognize the use of ontological ideas about the dynamics of the pathological process and its standardization.

Key words: health insurance, quality of care, risk of insurance activities, medical errors, identifies the root cause.

Вступление. Известно, что специфика медицинского страхования заключается во взаимодействии страховой компании с учреждениями здравоохранения и параллельной оценкой качества оказания медицинской помощи, однако, существует проблема отсутствия принятых механизмов выявления врачебных ошибок. Заключение договоров о страховании не подразумевает количественную оценку состояния пациента. Этот факт, а также то, что успех страхования в значительной мере зависит от качества оказания медицинских услуг учреждениями здравоохранения, приводит к существенному возрастанию рисков успешной деятельности страховых компаний.

Заметим, что проблема врачебных ошибок является одной из самых сложных во всем мире, поскольку их количество, к сожалению, не сокращается, а возрастает. Так, в США жертвами врачебных ошибок ежегодно становятся от 40 до 87 тыс. американцев. От врачебных ошибок погибает больше людей, чем, например, от СПИДа. По самым скромным подсчетам, экономический ущерб, ежегодно наносимый врачебными ошибками в США, приравнивается к государственному бюджету Российской Федерации. Таким образом, в судебной практике все чаще возникают дела (уголовные и гражданские) о врачебных ошибках. Медицинский персонал привлекают к уголовной ответственности, а клиники несут огромные убытки в виде компенсационных выплат за причиненный моральный ущерб и вред, причиненный здоровью. В данной цепи также задействованы и другие организации - страховые и фармацевтические компании. Первые часто обязаны выплачивать солидные суммы пациентам, а затем предъявляют регрессные иски медицинским учреждениям, что может стать для последних началом конца деятельности. Фармацевтические компании в свою очередь также могут быть привлечены к ответственности, например, за поставку некачественной продукции.

Более детальная статистика свидетельствует, что, например, в США около 1,5 миллиона человек в год страдают от принятых лекарственных средств (ЛС). При этом большинство медицинских ошибок от на- значенных ЛС нигде не фиксируются. Там же ежегодно около 100 тыс. человек умирают в результате медицинских ошибок, в Великобритании эта цифра составляет 70 тыс. человек. В больницах США происходит около 400 тыс. ошибок, связанных с медикаментами, или примерно одна медицинская ошибка на одного пациента в день. Еще 800 тыс. врачебных ошибок, обусловленных неправильным применением ЛС, происходят при долгосрочном уходе за пациентами (например, в доме престарелых) [1].

Ежегодно проводится более 7500 тысяч ненужных медицинских и хирургических процедур. В результате более половины населения США получили ненужное лечение (примерно 50000 человек в день). $42 \%$ человек был нанесен напрямую вред от врачебной ошибки, процедур или ЛС, причем 84 \% населения лично знают человека, ставшего жертвой врачебной ошибки $[2,3]$.

Использование рецептурных препаратов является третьей ведущей причиной смерти в США. По данным статистики, более 106 тыс. человек ежегодно умирают от побочных реакций ЛС, и только 6 \% всех побочных реакций должным образом идентифицированы.

Аналогичная ситуация имеет место и в Европе. Почти 4 из 5 граждан ЕС (78 \%) классифицировали медицинские ошибки, как важную проблему. $23 \%$ европейцев лично или кто-то из членов их семей непосредственно пострадали от врачебной ошибки, а $18 \%$ - стали жертвами серьезных медицинских ошибок в больнице. 11 \% жителей ЕС сообщили, что пострадали от неправильного назначения ЛС.

Так, по данным исследований, в Германии жертвами медицинских ошибок ежегодно становятся около 100 тыс. пациентов. По данным Испанской ассоциации жертв медицинской халатности, в Испании, где действует преимущественно государственная система здравоохранения, за последние 10 лет в результате ошибок врачей умерло более 5 тыс. пациентов. При этом лишь 10 \% жалоб на врачей рассматриваются судами в пользу пациентов, поскольку в стране активно внедряется «защитная медици- 
на». Особенно сложная ситуация в Италии, где система здравоохранения считается одной из самых эффективных и одновременно наиболее консервативных в Европе. По данным исследований, каждый год от медицинских ошибок страдают более 90 тыс. итальянцев. Наибольшее количество врачебных ошибок в больницах случаются в Латвии (32\%), Дании (29\%) и Польше (28 \%), Эстонии и Мальте (18\% каждая) [4].

В Украине ситуация не лучше. Однако, здесь статистика врачебных ошибок почти совсем закрыта, и лишь отдельные случаи становятся известны общественности, а судебная практика по данной категории дел не обнародуется.

В описанных условиях страховые компании подвергаются серьезным финансовым рискам.

Целью данной работы стало концептуальное определение механизмов выявления врачебных ошибок.

Результаты и их обсуждение. С появлением современной техники, новейших методов диагностики и лечения медицина не стала более точной наукой и менее рискованной практикой. Главное, что не определено понятие надлежащей медицинской помощи и понятие врачебной ошибки. Например, в Федеральном Законе Российской Федерации 우 5487 1 от 22 июля 1993 г. «Основы законодательства Российской Федерации об охране здоровья граждан» есть лишь упоминание о профессиональной ошибке, но ее содержание не раскрывается. В Кодексе Республики Казахстан № 193-1У от 18.09.2009 "О здоровье народа и системе здравоохранения" предусмотрено право граждан на обжалование действий (бездействия) медицинских работников и должностных лиц организаций здравоохранения, но также отсутствует понятие «врачебной ошибки».

Более того, сегодня нет и юридического понятия «ошибки в профессиональной медицинской деятельности». Как правило, Уголовные кодексы стран СНГ также не содержат норму, раскрывающую содержание врачебной (медицинской) ошибки. Наиболее часто используется следующие определения. «Врачебная ошибка» - ошибка врача в профессиональной деятельности, вследствие добросовестного заблуждения при отсутствии небрежности, халатности или невежества; «врачебная ошибка» - ошибка врача при исполнении своих профессиональных обязанностей, являющаяся следствием добросовестного заблуждения и не содержащая состава преступления или признаков проступков.

Однако, каждое из этих определений, в свою очередь, содержит в себе такое понятие как «добросо- вестное заблуждение», являющееся абсолютно не конкретным и допускающее многочисленные толкования.

В настоящем исследовании анализировались два возможных пути решения поставленной цели - нормативно-правовой и информационно-математический.

1. Нормативно-правовой путь страхования врачебной ошибки.

Развитие и распространение страхования профессиональной ответственности медицинских работников в настоящее время является одной из наиболее актуальных проблем в здравоохранении. Оно продиктовано насущной необходимостью повышения уровня правовой и социальной защиты, как пациентов, так и лиц, оказывающих медицинскую помощь. Кроме того, страховая защита нужна всему медицинскому персоналу на случай предъявления судебного иска пациентом (либо его представителем).

Необходимость развития данного вида страхования связана с ростом правосознания и юридической грамотности населения, а также упрощением процедуры предъявления исков в суде.

Страхование профессиональной ответственности представляет собой совокупность видов страхования, предусматривающих обязанности страховщика по страховым выплатам в размере полной или частичной компенсации ущерба, нанесенного объекту страхования. Таким образом, при заключении договора страхования профессиональной ответственности страховая компания принимает на себя обязательство полностью или частично, в зависимости от условий договора страхования, компенсировать страхователю или застрахованному лицу расходы, связанные с обязанностью последнего возместить ущерб (вред), причиненный жизни, здоровью или имуществу клиента в процессе своей профессиональной деятельности. Особенностью данного вида страхования является то, что застрахованное лицо должно обладать специализированными знаниями и определенной профессиональной подготовкой или иметь возможность получить консультацию специалиста, чтобы использовать их в ходе своей профессиональной деятельности.

Ответственность учреждения (клиники) базируется на обязанности: оказывать медицинскую помощь пациентам и нести солидарную ответственность за небрежность своих сотрудников. Вопрос о солидарной ответственности клиники в настоящее время остается спорным и дискуссионным не только в юридической литературе, но и в судебной практике. Нужно сказать, что решение этого важного вопроса 
зависит также от вида системы здравоохранения и национального законодательства в этой сфере. Вместе с тем, новые положения гражданского законодательства и нормативных актов, регулирующих оказание медицинских услуг на платной основе, позволяют при выполнении соответствующих условий возложить всю ответственность за врачебную ошибку на врача и освободить клинику от солидарной ответственности.

На практике же ситуация не соответствует теоретическим расчетам. Большинство пациентов непрерывно повышают свои требования. Размеры исков существенно превышают ущерб, нанесенный пациенту. Пациент считает, что потерял время и получил моральный ущерб. При нелимитированной ответственности суды до настоящего времени эти претензии по большей части удовлетворяли. Соответственно, страховщики получали прямые убытки. Так, Франция, одна из самых благополучных стран мира по медицине, не находит решения, в первую очередь, в результате изменения законодательства в сторону защиты интересов пациентов. В свою очередь страховые компании не могут больше участвовать в данном виде страхования. Пять крупнейших страховых компаний расторгли соответствующие договора с клиниками. В европейской стране, где все понимают, что страховаться необходимо, к декабрю 2012 года из 1200 ведущих частных клиник половина была не застрахована.

Казалось, что тяжесть последствий можно сгладить, компенсировав причиненный ущерб. Признанным во всем мире инструментом является страхование профессиональной ответственности. Он позволяет цивилизованно разрешить конфликты между врачами и пациентами. Врачи защищены от разорения и необоснованных исков. А пациентам намного проще взыскать компенсацию, если доктор застрахован.

Однако, и этот путь представляет большие труд ности. Так, в Российской Федерации начато общественное обсуждение законопроекта о страховании населения от врачебных ошибок. Законопроект в середине апреля 2013 года был размещен на официальном сайте Минздрава России для общественного обсуждения. Документ вводит понятие врачебная ошибка - действие или бездействие, в результате которого нанесен вред здоровью человека. Предполагается, что медицинские организации будут обязаны осуществлять страхование пациентов. С момента начала общественного обсуждения проекта закона на протяжении 4 месяцев не было полу- чено ни одного отклика в его поддержку. Критикуется как концепция законопроекта, так и сами принципы страхования. Врачам не понятно, что в результате страхуется, кто и за что несет ответственность, как проект закона влияет на снижение числа врачебных ошибок.

Поэтому на сегодняшний день нам представляется более практичным использование информационных подходов для выявления врачебных ошибок.

2. Информационно-математический путь выявления врачебной ошибки.

Отправной точкой работы по улучшению качества медицинской помощи обычно является проблема, обнаруженная и идентифицированная человеком или группой людей, желающих добиться одинаковой цели. А необходимым условием решения проблемы является определение и устранение ее основной причины. Только в этом случае вы можете быть уверены, что проблема действительно решена.

Для того, чтобы быстро добраться до основной причины проблемы и улучшить процесс, многие специалисты по решению проблем используют подход, называемый анализ основной причины. Для его реализации используют различные методологии: тестирования и оценки предложений до принятия окончательного решения; вовлечение в процесс решения проблемы тех, кто знает ее лучше всего; рассмотрение процесса решения проблемы как части общего процесса улучшений.

Остановимся на некоторых формализованных алгоритмах.

I. Применение колеса Деминга или цикла «Планируй - Выполняй - Проверяй - Действуй». Метод демонстрирует систематический и непрерывный подход к решению проблемы. За четыре этапа проблема анализируется, предпринимаются корректирующие мероприятия, оценивается их результативность и процесс модернизируется путем внедрения мероприятий, дающих желаемый результат.

В общем случае рассматривается 6 этапов: идентификация проблемы, формулировка проблемы, осознание проблемы, идентификация основной причины, устранение основной причины, мониторинг симптомов.

В свою очередь, для каждого из них существуют свои алгоритмы. Так, для определения проблемы применяют блок-схемы (диаграмма, критический случай - подход, используемый для анализа наиболее критических случаев в сложившейся ситуации, радарная диаграмма - диаграмма для проведения сравнительного анализа, матрица влияния - используется для определения важности проблем или причин). 
В процессе поиска вероятной причины и достижения консенсуса применяются: мозговой штурм, письменный мозговой штурм, метод формальной группы, попарное сравнение.

Для сбора информации о врачебной ошибке и ее причине можно задействовать: принцип организации выборки (извлечение данных из больших объемов информации), метод опроса, метод проверочного листка (для систематического сбора информации с использованием заранее подготовленных листов), метод гистограмм, диаграмму Парето, диаграмму рассеивания (для представления взаимосвязи между парами причин или других параметров, связанных с проблемой), диаграмму зависимостей (для идентификации логических взаимосвязей между разными идеями или вопросами, связанными с проблемой), аффинную диаграмму (для выявления связи между идеями и причинами).

Причинно-следственный анализ, как правило, использует причинно-следственную диаграмму для анализа возможных причин проблемы и матричную диаграмму для упорядочивания данных.

Применяются также подходы: радарной диаграммы; бенчмаркинга, матрицы влияния, диаграмма Ишикавы и многие другие.

II. На современном этапе развития науки и технологий наиболее перспективным мы считаем использование онтологических представлений о динамике патологического процесса и его стандартизацию.

Онтология представляет собой описание декларативных знаний, сделанное в виде классов с отноше-

\section{Литература}

1. Medical error statistics : [Электронный ресурс]. - Режим доступа: http://www.answer-my-health-question.info/medicalerror-statistics.html.

2. Medical malpractice statistics for Medication errors : [Электронный ресурс]. - Режим доступа: http:// www.rightdiagnosis.com $/ \mathrm{m} /$ medication errors $/$ stats.htm.

3. Medication Error Stats \& Examples : [Электронный peсурс] - Режим доступа : http://www.alcooklaw.com/practiceareas/medication-error-injury/ medication-error-statsexamples/.

4. Special EUROBAROMETER 241 "MEDICAL ERRORS" : [Электронный pecypc]. - Режим доступа : http:// нием иерархии между ними. К этому описанию, предназначенному для чтения человеком, присоединено описание в канонической форме, которое предназначено для чтения машинами. Каждая интеллектуальная система может предоставлять несколько таких описаний, соответствующих различным областям хранящихся в ней декларативных знаний и, таким образом, выступает как хранилище библиотеки онтологий. То есть, онтология является попыткой всеобъемлющей и детальной формализации клинических знаний.

Онтологии используются для построения концептуальной модели, т.е. модели предметной области, состоящей из перечня взаимосвязанных понятий, используемых для описания этой области, вместе со свойствами и характеристиками, классификацией этих понятий по типам, ситуациям, признакам в данной области и законов протекания процессов в ней. Таким образом, создается унифицированная конструкция для отображения знаний, представляющая собой множество объектов, классифицированных в соответствии с критериями, крайне необходимыми для построения страховых моделей.

Выводы. 1. Информационные технологии в медицинском страховании имеют высокую значимость для формализованного описания патологического процесса.

2. Использование онтологических представлений о динамике патологического процесса и его стандартизации является возможным и перспективным подходом для выявления врачебных ошибок.

ec.europa.eu/public_opinion/archives/ ebsZebs_241_en.pdf. 5. Бельская Е. В. Право на страхование врачебной ошибки / Бельская Е. В., Киселев М. П., Волчанина Е. Н. // Медицина. - 2004. - №> 3. - С. 2-3.

6. Дятлов М. М. Ошибки при оказании помощи пострадавшим с травматическими вывихами голени / М. М. Дятлов, С. Н. Кириленко // Медицинские новости. - 2006. - №2 5. - С. 123-126.

7. Ерофеев С. В. Медико-правовые аспекты оценки качества медицинской помощи: сравнение отечественной и зарубежной практики / С. В. Ерофеев // Медицинское право. - 2006. - №> 1. - С. 39-43. 